\title{
Approximate perfect differential equations of second order
}

\author{
Mohammad Reza Abdollahpour ${ }^{1}$, Abbas Najati' , Choonkil Park², Themistocles M Rassias ${ }^{3}$ and Dong
} Yun Shin ${ }^{4 *}$

Correspondence: dyshin@uos.ac.kr ${ }^{4}$ Department of Mathematics, University of Seoul, Seoul, 130-743, Korea

Full list of author information is available at the end of the article

\begin{abstract}
In this paper we prove the Hyers-Ulam stability of the perfect linear differential equation $f(t) y^{\prime \prime}(t)+f_{1}(t) y^{\prime}(t)+f_{2}(t) y(t)=Q(t)$, where $f, y \in C^{2}[a, b], Q \in C[a, b]$, $f_{2}(t)=f_{1}^{\prime}(t)-f^{\prime \prime}(t)$ and $-\infty<a<b<+\infty$.

MSC: 34K20; 26D10; 39B82; 34K06; 39B72
\end{abstract}

Keywords: Hyers-Ulam stability; differential equation

\section{Introduction}

The question concerning the stability of group homomorphisms was posed by Ulam [1]. Hyers [2] solved the case of approximately additive mappings in Banach spaces and T.M. Rassias generalized the result of Hyers [3].

Definition 1.1 Let $X$ be a normed space over a scalar field $\mathbb{K}$ and let $I$ be an open interval. Assume that $a_{0}, a_{1}, \ldots, a_{n}, h: I \rightarrow \mathbb{K}$ are continuous functions. We say that the differential equation

$$
a_{n}(t) y^{(n)}(t)+a_{n-1}(t) y^{(n-1)}(t)+\cdots+a_{1}(t) y^{\prime}(t)+a_{0}(t) y(t)+h(t)=0
$$

has the Hyers-Ulam stability if, for any function $f: I \rightarrow X$ satisfying the differential inequality

$$
\left\|a_{n}(t) y^{(n)}(t)+a_{n-1}(t) y^{(n-1)}(t)+\cdots+a_{1}(t) y^{\prime}(t)+a_{0} y(t)+h(t)\right\| \leq \varepsilon
$$

for all $t \in I$ and some $\varepsilon \geq 0$, there exists a solution $g: I \rightarrow X$ of (1.1) such that $\|f(t)-g(t)\| \leq$ $K(\varepsilon)$ for all $t \in I$, where $K(\varepsilon)$ is a function depending only on $\varepsilon$.

Obłoza $[4,5]$ was the first author who investigated the Hyers-Ulam stability of differential equations (also see [6]).

Jung [7] solved the inhomogeneous differential equation of the form $y^{\prime \prime}+2 x y^{\prime}-2 n y=$ $\sum_{m=0}^{\infty} a_{m} x^{m}$, where $n$ is a positive integer, and he used this result to prove the Hyers-Ulam stability of the differential equation $y^{\prime \prime}+2 x y^{\prime}-2 n y=0$ in a special class of analytic functions.

Li and Shen [8] proved that if the characteristic equation $\lambda^{2}+\alpha \lambda+\beta=0$ has two different positive roots, then the linear differential equation of second order with constant

(c) 2012 Abdollahpour et al: licensee Springer. This is an Open Access article distributed under the terms of the Creative Commons Attribution License (http://creativecommons.org/licenses/by/2.0), which permits unrestricted use, distribution, and reproduction in any medium, provided the original work is properly cited. 
coefficients $y^{\prime \prime}(x)+\alpha y^{\prime}(x)+\beta y(x)=f(x)$ has the Hyers-Ulam stability where $y \in C^{2}[a, b]$, $f \in C[a, b]$ and $-\infty<a<b<+\infty$ (see also [9, 10]). Abdollahpour and Najati [11] proved that the third-order differential equation $y^{(3)}(t)+\alpha y^{\prime \prime}(t)+\beta y^{\prime}(t)+\gamma y(t)=f(t)$ has the HyersUlam stability. Ghaemi et al. [12] proved the Hyers-Ulam stability of the exact secondorder linear differential equation

$$
p_{0}(x) \gamma^{\prime \prime}+p_{1}(x) \gamma^{\prime}+p_{2}(x) \gamma+f(x)=0
$$

with $p_{0}^{\prime \prime}(x)-p_{1}^{\prime}(x)+p_{2}(x)=0$. Here $p_{0}, p_{1}, p_{2}, f:(a, b) \rightarrow \mathbb{R}$ are continuous functions. For more results about the Hyers-Ulam stability of differential equations, we can refer to [13-21].

Definition 1.2 We say that the differential equation

$$
f(t) y^{\prime \prime}(t)+f_{1}(t) y^{\prime}(t)+f_{2}(t) y(t)=Q(t)
$$

is perfect if it can be written as $\frac{d}{d t}\left[f(t) y^{\prime}(t)+\left(f_{1}(t)-f^{\prime}(t)\right) y(t)\right]=Q(t)$.

It is clear that the differential equation (1.2) is perfect if and only if $f_{2}(t)=f_{1}^{\prime}(t)-f^{\prime \prime}(t)$. The aim of this paper is to investigate the Hyers-Ulam stability of the perfect differential equation (1.2), where $f, y \in C^{2}[a, b], Q \in C[a, b], f_{1} \in C^{1}[a, b], f_{2}(t)=f_{1}^{\prime}(t)-f^{\prime \prime}(t)$ and $-\infty<$ $a<b<+\infty$. More precisely, we prove that the equation (1.2) has the Hyers-Ulam stability.

\section{Hyers-Ulam stability of the perfect differential equation}

$$
f(t) y^{\prime \prime}(t)+f_{1}(t) y^{\prime}(t)+f_{2}(t) y(t)=Q(t)
$$

In the following theorem, we prove the Hyers-Ulam stability of the differential equation (1.2).

Throughout this section, $a$ and $b$ are real numbers with $-\infty<a<b<+\infty$.

Theorem 2.1 The perfect differential equation

$$
f(t) y^{\prime \prime}(t)+f_{1}(t) y^{\prime}(t)+f_{2}(t) y(t)=Q(t)
$$

has the Hyers-Ulam stability, where $f, y \in C^{2}[a, b], f_{1} \in C^{1}[a, b], Q \in C[a, b]$ and $f(t) \neq 0$ for all $t \in[a, b]$.

Proof Let $\varepsilon>0$ and $y \in C^{2}[a, b]$ with

$$
\left|f(t) y^{\prime \prime}(t)+f_{1}(t) y^{\prime}(t)+f_{2}(t) y(t)-Q(t)\right| \leq \varepsilon \text {. }
$$

Let $g(t)=f(t) y^{\prime}+\left(f_{1}(t)-f^{\prime}(t)\right) y$ for all $t \in[a, b]$. It is clear that

$$
\left|g^{\prime}(t)-Q(t)\right|=\left|f(t) y^{\prime \prime}(t)+f_{1}(t) y^{\prime}(t)+f_{2}(t) y(t)-Q(t)\right| \leq \varepsilon .
$$

We define

$$
z(x)=g(b)-\int_{x}^{b} Q(t) d t, \quad x \in[a, b] .
$$


Then

$$
z^{\prime}(x)=Q(x), \quad x \in[a, b] .
$$

Also, we have

$$
\begin{aligned}
|z(x)-g(x)| & =\left|g(b)-g(x)-\int_{x}^{b} Q(t) d t\right|=\left|\int_{x}^{b} g^{\prime}(t) d t-\int_{x}^{b} Q(t) d t\right| \\
& \leq \int_{x}^{b}\left|g^{\prime}(t)-Q(t)\right| d t \leq \varepsilon(b-a)
\end{aligned}
$$

for all $x \in[a, b]$. Now we define

$$
F(x)=\frac{1}{f(x)} \exp \left\{\int_{a}^{x} \frac{f_{1}(t)}{f(t)} d t\right\}, \quad u(x)=\frac{y(b) F(b)}{F(x)}-\frac{1}{F(x)} \int_{x}^{b} \frac{z(t) F(t)}{f(t)} d t
$$

for all $x \in[a, b]$. It is clear that $u \in C^{2}[a, b]$ and

$$
u^{\prime}(x) F(x)+u(x) F^{\prime}(x)=\frac{z(x) F(x)}{f(x)}, \quad F^{\prime}(x)=\frac{f_{1}(x)-f^{\prime}(x)}{f(x)} F(x) .
$$

Therefore,

$$
f(x) u^{\prime}(x)+\left[f_{1}(x)-f^{\prime}(x)\right] u(x)=z(x), \quad x \in[a, b] .
$$

Hence, (2.1) implies that

$$
f(x) u^{\prime \prime}(x)+f_{1}(x) u^{\prime}(x)+f_{2}(x) u(x)=Q(x), \quad x \in[a, b] .
$$

Also, we have

$$
\begin{aligned}
|y(x)-u(x)| & =\left|y(x)-\frac{y(b) F(b)}{F(x)}+\frac{1}{F(x)} \int_{x}^{b} \frac{z(t) F(t)}{f(t)} d t\right| \\
& =\frac{1}{|F(x)|}\left|y(x) F(x)-y(b) F(b)+\int_{x}^{b} \frac{z(t) F(t)}{f(t)} d t\right| \\
& =\frac{1}{|F(x)|}\left|\int_{x}^{b} \frac{z(t) F(t)}{f(t)} d t-\int_{x}^{b}[y(t) F(t)]^{\prime} d t\right| \\
& =\frac{1}{|F(x)|}\left|\int_{x}^{b}\left(\frac{z(t) F(t)}{f(t)}-y^{\prime}(t) F(t)-y(t) F^{\prime}(t)\right) d t\right| \\
& =\frac{1}{|F(x)|}\left|\int_{x}^{b} F(t)\left(\frac{z(t)}{f(t)}-y^{\prime}(t)-\frac{f_{1}(t)-f^{\prime}(t)}{f(t)} y(t)\right) d t\right| \\
& \leq \frac{1}{|F(x)|} \int_{x}^{b}\left|\frac{F(t)}{f(t)}\right|\left|z(t)-y^{\prime}(t) f(t)-\left[f_{1}(t)-f^{\prime}(t)\right] y(t)\right| d t \\
& =\frac{1}{|F(x)|} \int_{x}^{b}\left|\frac{F(t)}{f(t)}\right||z(t)-g(t)| d t \\
& \leq \varepsilon(b-a) \frac{1}{|F(x)|} \int_{x}^{b}\left|\frac{F(t)}{f(t)}\right| d t
\end{aligned}
$$


for all $x \in[a, b]$. Since $\frac{f_{1}}{f} \in C[a, b]$, there exist constants $m^{\prime}$ and $M^{\prime}$ such that $m^{\prime} \leq \frac{f_{1}(x)}{f(x)} \leq$ $M^{\prime}$. Thus

$$
\begin{cases}1 \leq \exp \left\{\int_{a}^{x} \frac{f_{1}(t)}{f(t)} d t\right\} \leq e^{M^{\prime}(b-a)} & \text { if } m^{\prime} \geq 0 \\ e^{m^{\prime}(b-a)} \leq \exp \left\{\int_{a}^{x} \frac{f_{1}(t)}{f(t)} d t\right\} \leq e^{M^{\prime}(b-a)} & \text { if } m^{\prime}<0 \leq M^{\prime} \\ e^{m^{\prime}(b-a)} \leq \exp \left\{\int_{a}^{x} \frac{f_{1}(t)}{f(t)} d t\right\} \leq 1 & \text { if } M^{\prime}<0\end{cases}
$$

for all $x \in[a, b]$. Since $f \in C[a, b]$ and $|f|>0$, there exist constants $0<m \leq M$ such that $m \leq|f(x)| \leq M$ for all $x \in[a, b]$. Hence, (2.4) implies that

$$
\frac{1}{M} e^{\left|m^{\prime}\right|(a-b)} \leq|F(x)| \leq \frac{1}{m} e^{\left|M^{\prime}\right|(b-a)}
$$

for all $x \in[a, b]$. It follows from (2.3) that

$$
\begin{aligned}
|y(x)-u(x)| & \leq \varepsilon(b-a) \frac{1}{|F(x)|} \int_{x}^{b}\left|\frac{F(t)}{f(t)}\right| d t \\
& \leq \varepsilon(b-a)^{2} \frac{M}{m^{2}} e^{\left(\left|m^{\prime}\right|+\left|M^{\prime}\right|\right)(b-a)}
\end{aligned}
$$

for all $x \in[a, b]$.

\section{Competing interests}

The authors declare that they have no competing interests.

\section{Authors' contributions}

All authors conceived of the study, participated in its design and coordination, drafted the manuscript, participated in the sequence alignment, and read and approved the final manuscript.

\section{Author details}

${ }^{1}$ Department of Mathematics, Faculty of Sciences, University of Mohaghegh Ardabili, Ardabil, 56199-11367, Iran.

${ }^{2}$ Department of Mathematics, Research Institute for Natural Sciences, Hanyang University, Seoul, 133-791, Korea.

${ }^{3}$ Department of Mathematics, National Technical University of Athens, Zografou Campus, Athens, 15780, Greece.

${ }^{4}$ Department of Mathematics, University of Seoul, Seoul, 130-743, Korea.

\section{Acknowledgements}

CP was supported by the Basic Science Research Program through the National Research Foundation of Korea funded by the Ministry of Education, Science and Technology (NRF-2012R1A1A2004299) and DYS was supported by the Basic Science Research Program through the National Research Foundation of Korea funded by the Ministry of Education, Science and Technology (NRF-2010-0021792)

Received: 3 September 2012 Accepted: 21 November 2012 Published: 27 December 2012

\section{References}

1. Ulam, SM: Problems in Modern Mathematics. Wiley, New York (1940)

2. Hyers, DH: On the stability of the linear functional equation. Proc. Natl. Acad. Sci. USA 27, $222-224$ (1941)

3. Rassias, TM: On the stability of linear mapping in Banach spaces. Proc. Am. Math. Soc. 72, 297-300 (1978)

4. Obłoza, M: Hyers stability of the linear differential equation. Rocznik Nauk.-Dydakt. Prace Mat. 13, $259-270$ (1993)

5. Obłoza, M: Connections between Hyers and Lyapunov stability of the ordinary differential equations. Rocznik Nauk.-Dydakt. Prace Mat. 14, 141-146 (1997)

6. Alsina, C, Ger, R: On some inequalities and stability results related to the exponential function. J. Inequal. Appl. 2, 373-380 (1998)

7. Jung, S: Hyers-Ulam stability of differential equation $y^{\prime \prime}+2 x y^{\prime}-2 n y=0$. J. Inequal. Appl. 2010, Article ID 793197 (2010)

8. Li, Y, Shen, Y: Hyers-Ulam stability of linear differential equations of second order. Appl. Math. Lett. 23, 306-309 (2010)

9. Eshaghi Gordji, M, Cho, Y, Ghaemi, MB, Alizadeh, B: Stability of the exact second order partial differential equations. J. Inequal. Appl. 2011, Article ID 306275 (2011)

10. Najati, A, Abdollahpour, MR, Cho, Y: Superstability of linear differential equations of second order. Preprint

11. Abdollahpour, MR, Najati, A: Stability of linear differential equations of third order. Appl. Math. Lett. 24, 1827-1830 (2011) 
12. Ghaemi, MB, Eshaghi Gordji, M, Alizadeh, B, Park, C: Hyers-Ulam stability of exact second order linear differential equations. Adv. Differ. Equ. 2012, Article No. 36 (2012)

13. Gavruta, P, Jung, S, Li, Y: Hyers-Ulam stability for second-order linear differential equations with boundary conditions. Electron. J. Differ. Equ. 2011(80), 1-5 (2011)

14. Jung, S: Hyers-Ulam stability of linear differential equations of first order. Appl. Math. Lett. 17, 1135-1140 (2004)

15. Jung, S: Hyers-Ulam stability of linear differential equations of first order, III. J. Math. Anal. Appl. 311, 139-146 (2005)

16. Jung, S: Hyers-Ulam stability of linear differential equations of first order, II. Appl. Math. Lett. 19, $854-858$ (2006)

17. Miura, T: On the Hyers-Ulam stability of a differentiable map. Sci. Math. Jpn. 55, 17-24 (2002)

18. Miura, T, Miyajima, S, Takahasi, SE: Hyers-Ulam stability of linear differential operators with constant coefficients. Math Nachr. 258, 90-96 (2003)

19. Miura, T, Jung, S, Takahasi, SE: Hyers-Ulam-Rassias stability of the Banach space valued differential equations $y^{\prime}=\lambda y$ J. Korean Math. Soc. 41, 995-1005 (2004)

20. Popa, D, Rasa, I: On the Hyers-Ulam stability of the differential equation. J. Math. Anal. Appl. 381, $530-537$ (2011)

21. Popa, D, Rasa, I: On the Hyers-Ulam stability of the differential operator with nonconstant coefficients. Appl. Math. Comput. 219, 1562-1568(2012)

doi:10.1186/1687-1847-2012-225

Cite this article as: Abdollahpour et al.: Approximate perfect differential equations of second order. Advances in Difference Equations 2012 2012:225.

\section{Submit your manuscript to a SpringerOpen ${ }^{\circ}$ journal and benefit from:}

- Convenient online submission

- Rigorous peer review

Immediate publication on acceptance

- Open access: articles freely available online

- High visibility within the field

- Retaining the copyright to your article 